POLLACK PERIODICA

An International Journal for Engineering and Information Sciences

DOI: $10.1556 / 606.2016 .11 .1 .12$

Vol. 11, No.1, pp. 129-143 (2016)

www.akademiai.com

\title{
THOUGHTS FROM THE DYNAMICAL CHANGING CITY, SHANGHAI
}

\author{
János GYERGYÁK \\ Department of Urban Studies Design, Faculty of Engineering and Information Technology, \\ University of Pécs, Rókus u. 2, H-7624 Pécs, Hungary \\ e-mail: gyergyak.janos@pmmik.pte.hu
}

Received 6 March 2015; accepted 21 September 2015

\begin{abstract}
The paper represents the rapidly developing cities in China, namely Shanghai. The metropolis has become a show-case city of the Chinese economy in the last couple of decades. By means of vast investments Shanghai is constantly being renewed and re-edified. The goal of the paper is to present the transformation of the existing conditions, related to public spaces through scientific and empirical elements.
\end{abstract}

Keywords: Urbanism, Urban design, Urban development, Urban development strategy, Public square, City life, Public space, Future of the cities

\section{Urban development as the engine of economic investment}

The amazing economic growth of the last decades in China was mainly about industrial developments and the expansion of commerce. The artificially formed enormous surfaces, which involve these 'tiny' urban tissues, were hardly ever mentioned. The development of the Chinese cities is one of the most significant architectural performances [1] of the $21^{\text {th }}$ century. Instead of quality, the emphasis is on quantity in this case. Due to the great pace of the Chinese urban development, the vast majority of inhabitants live [1] in an urban environment nowadays. Considering the large number of population, this means renewed living conditions and living environment of huge masses of people, which were constructed almost from one week to another. If it is thought for a second, that according to some studies 300-400 million people will be living in an urban environment in the next 15 years in order to possess 
better living standards, it can be bluntly stated that the development has not yet been over [2].

The well-known and massive-sized agglomerations are not able to absorb huge crowds of people appropriately in spite of the continuous expansions. To reach the desired goal of the Chinese state, namely becoming a leading economic power of the world, urbanization is one of the fundamental tools. Shanghai is the center of industrial production, investments and services, with other words the center of capital. Urban people earn much more money in comparison with rural inhabitants, but they have to spend this surplus almost immediately, since urban life and its services cost a considerable amount of money. How long can these cities develop? How far can they expand? Do they have a human dimension? How do public 'free' surfaces transform?

Urban development, the growth and alteration of city size in China have occurred through two different urbanization processes in the last 30 years. One is typically social, whereas the other is based clearly on economic factors [1]. The former type is the socalled 'urban village', which possesses mainly the improvements on the edges of the inner city, namely in the suburbs. It shows 'rustic' (small-towns) nature in terms of street view and functions. This atmosphere is fed by strong social coherence and the respect for old and new values. The inhabitants of these places are normally local residents, who have lost ground or moved from inland areas, or they are workers from other regions. The resulting diversity together with the old and new values creates a new urban life, which is related to the past. If life and development are guided by a community, it can be compared to the well-known grassroots urban development process (community led).

The other type of urban development is completely different from the previous one. Government-administered urbanization is clearly profit-oriented. The areas of several acres were developed by means of investment programs, without any detailed documentation plan. The self-government naturally ignores rundown and inhabited areas and with a simple decision these places are completely demolished and offered for sale as empty block sites. The formerly built typical dwelling-houses or industrial buildings do not meet the average living standards of today, but due to demolishing and reorganization the community of the residents and the buildings of the past are disappearing gradually. The usual 'demolish and vacant land' policy is vastly successful, since the area is the property of the state, so the preparation of the building sites for the developers occurs swiftly (in many cases with a significant amount of compensation towards the previous residents). Beyond all these, governmental considerations equally support constructions in agricultural areas. Huge development companies, related to these places, work out consolidated 'schema' functions and the architectural image: enclosed residential areas with access control system, shopping centers, commercial quarters with office buildings and service facilities. The suburban counterpart of the developments is the industrial improvement on the edges of the city (Fig. 1).

The correlation of the two distinctive types of urbanization is that they alter the built environment rather quickly. However, it is vastly essential, that these block sites and their different styles pre-define the surface and use of common outside spaces. Traditional street-like, slum-like, unbroken rows and their facades determine those surfaces, which can clearly be used, therefore the traditional street view is full of life 
and 'eventful'. Restaurants and shops on the ground floor, mobile hawkers on the streets generate the feeling of constant medley, providing real life for the city. On the other hand, the 'latest', almost in every case detached construction, with the open nature of spaces, cannot offer programs for people. At many places outer space becomes empty due to the distance or the closed nature of facades.

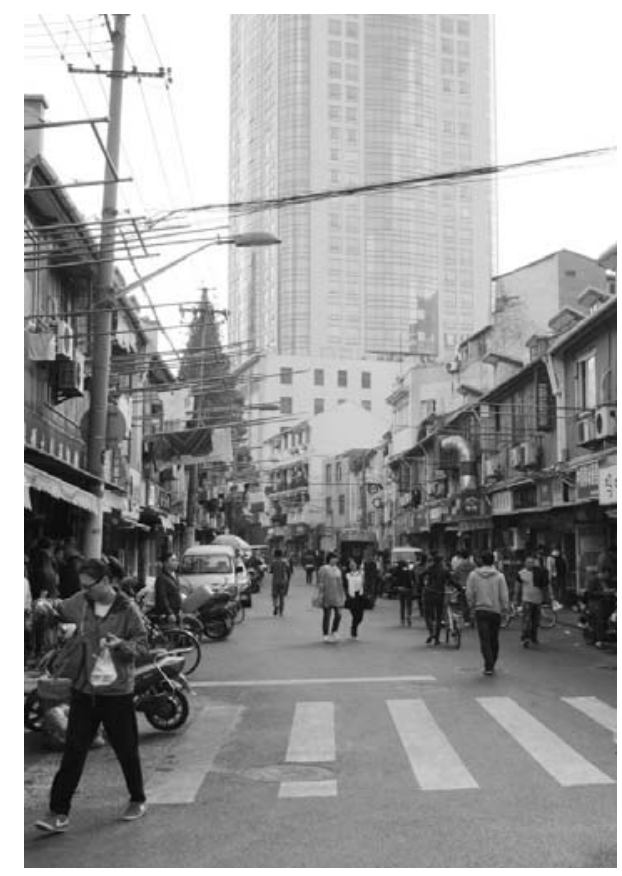

Fig. 1. An example of 'government-administered urbanization', which creates residential areas and shopping centers within the inner fabric, Source: János Gyergyák

\section{The transformation of Shanghai (EXPO 2010 )}

Shanghai lies in the middle of the East China seacoast, at the delta of river Yangtze and on both banks of the influent of Huangpu. Its urban population is the most considerable in the country. It can clearly be stated that Shanghai has become one of the huge commercial centers of the world and it is still being constructed amazingly fast. If its past is concerned, Chinese traditions (constructions, forms and facades) were mingled in tandem with western urbanism (suburban movements, modern beliefs). The city has had several significant development stages, during which the tiny fishing village has become a gigantic metropolis. These distinctive phases would deserve a separate article; therefore merely a couple of important steps are going to be mentioned here about the rapid growth of Shanghai.

The city plan of 1986 plainly explained the goals of the central Chinese leadership [1]. One of these was to transform Shanghai, with its significant international relations 
and past, into one of the most industrialized regions. It was crucial to own the largest port of the world, in order to rule the maritime transportation of the Pacific Ocean. The long-term goal was to convert the city into the center of the Chinese economy, technology, commerce, finance and culture (city with four poles in the future). This was only a vision at the beginning, but since then it has come true and nowadays Shanghai is the most considerable economic and commercial center on the western coast of the Pacific Ocean [3] (Fig. 2).

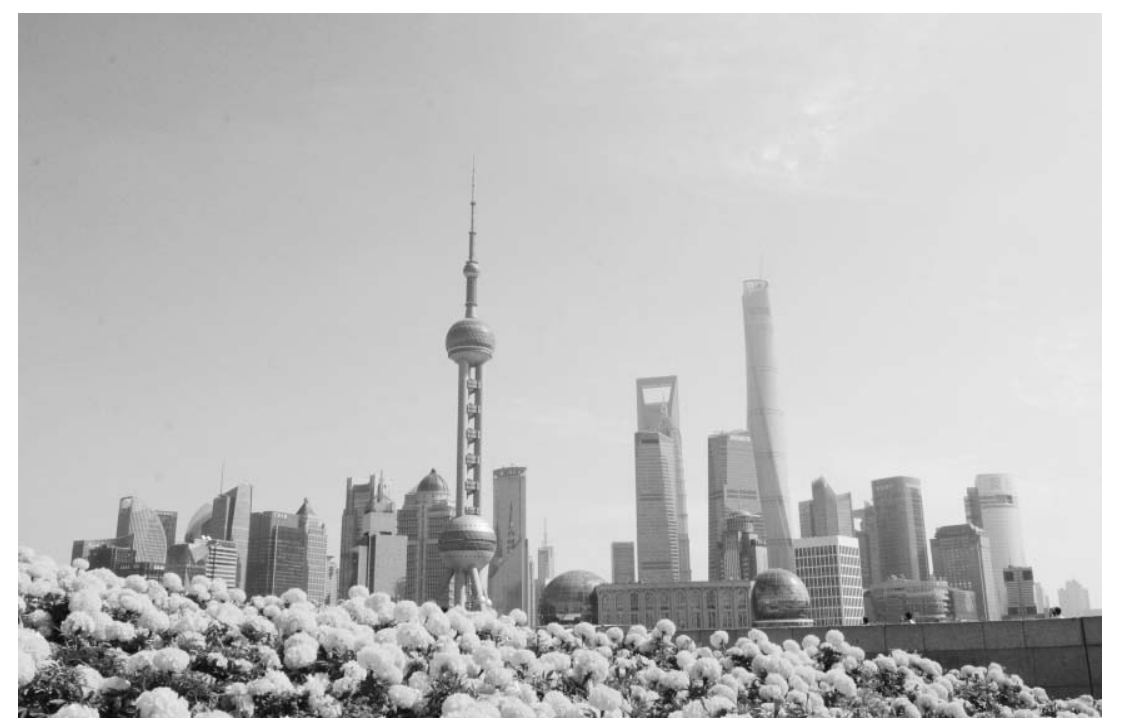

Fig. 2. Shanghai - Pudong commercial district. Separated road and pedestrian traffic, and the futuristic view of the taller and taller skyscrapers is in contrast with the other side of river Huangpu (Puxi), Source: János Gyergyák

Right after this another bright era, the latest blooming of the city, began in 1991, which was fundamentally triggered by the inner commercial core of the settlement, by means of constructing the skyscrapers of Pudong. Apart from being an important cultural and historical center, by 1999 Shanghai became the determinant maritime and economic center of China. The city had gradually become a chief international competitor and a metropolis, following the policies of social modernism. During this era the inner city was developed and transformed further together with forming additional satellite cities. This period 'ended' with the Shanghai Expo 2010. The transformation occurred with the following slogan: 'better city, better life', and its message is worth looking at closely.

The World Expo in 2010 can be mentioned together with the Olympic Games of Beijing in 2008, which was one of the most significant propaganda events of the economic development in China. It was an intermediate element of a grand improvement, which proudly shows the overwhelming momentum of the Chinese economy. In the history of Expos, it was the first one, which chose cities as its main theme (in five years' time the world has changed enormously and it can be exemplified 
by the theme of the Expo will be held this year, which concentrated mainly on rural values. Here is the slogan of Milano: 'Feeding the Planet, Energy for Life!'). The Expo emphasizes the fact that the vast majority of the population on planet Earth consciously choose urban areas for their home or living, therefore developing these places deserves more attention, so cities of the future will be able to improve within an appropriate framework. Now, five years later, there is a chance for evaluation, or judgment of the elevated thoughts from that time, with knowing the scales of urban development this period is a medium-term program, in which many goals can be achieved. What were these Expo thoughts from 2010? The main message of the Expo contained both economic and social points. It clearly connected the economic growth to cities ('economic prosperity in the city') and in parallel with this focused on incorporating different cultural values ('blending of diverse culture in the city'). Furthermore, it intended to form communities in a 'planned' way ('remodeling of communities in the city’), which seems to be forced or perhaps overly artificial nowadays (Fig. 3).

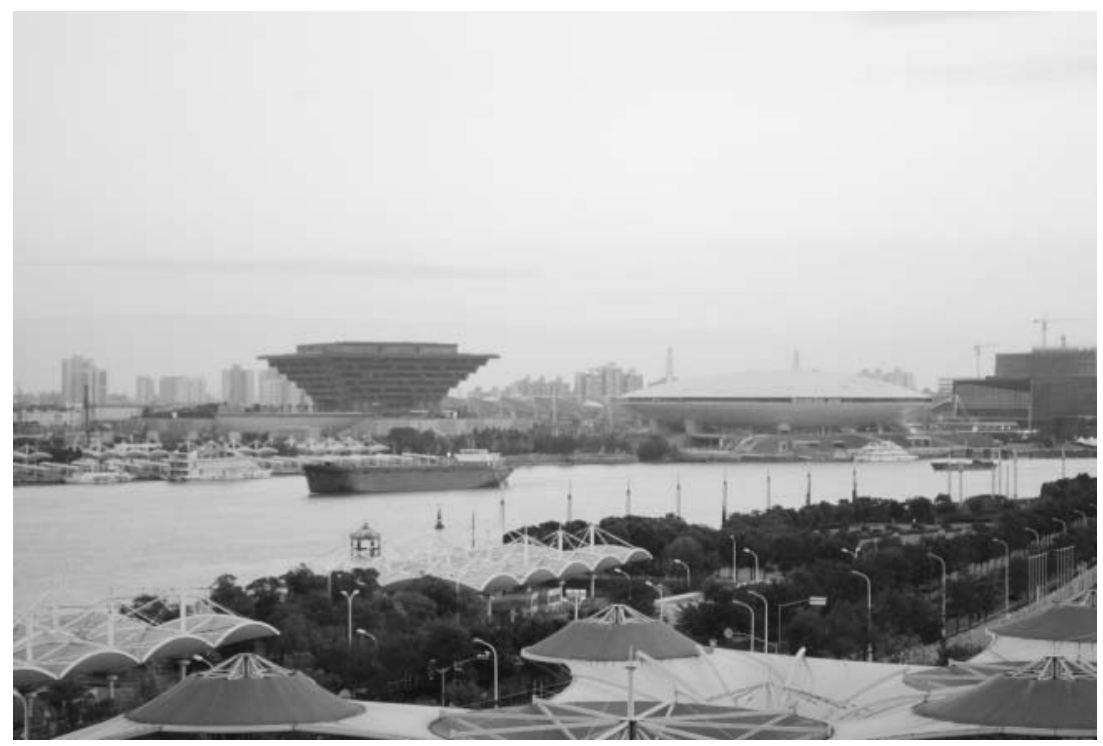

Fig. 3. The China pavilion at Shanghai Expo and the perspective view of Mercedes-Benz arena from the former Expo area, Source: János Gyergyák

The Expo attempted to answer two questions: how viable is it to make cities better, or inversely, what sort of cities can make life better. It had an important message, namely that cities depend on people and they can be considered as the soul of cities (Shanghai Expo 2010). These places have to strive for creating massive groups of people, the so called 'cells', and preserving diversity, thus generating vivid life by different cultures. It can be observed that the most considerable thoughts of the Expo dealt with cities and their inhabitants, people. This statement is rather appropriate, since cities and mainly the use of their common spaces is closely related to culture and society. How does the use of common spaces change, if the previous residents disappear 
and they are replaced by completely different communities (gentrification)? How can the past and the future of public spaces be described?

The alteration of public spaces and their actual use were analyzed in terms of streets, squares, parks (gardens) and waterside surfaces by means of a two-month-long research, in one of the most dynamically developing cities of today, Shanghai. This examination focuses on the formerly-built areas of certain public places and some newly-built ones as well. This writing is based on mainly personal experiences, complemented with studies and publications of researchers and town planners.

\subsection{Streets}

Having analyzed the public surfaces of Shanghai, it can be claimed that their most active parts are obviously streets. The traditional street in China is full of life and intensive. The open nature and attraction of facades generate vivid living spaces. Doing their business typically on the ground floor, the locals live upstairs and try to exploit the given ground-space fully as their only income source. Streets, which are usually defined as primary urban platforms for moving, attract pedestrians for stopping, looking around and enjoying pleasant urban living. However, this experience is often attached to smells, trash or disturbing noises, but in a human-scale space and friendly environment, which can be full of attractions for western people. Streets generally serve as platforms for pedestrian and road traffic, mostly without separation. The human-scale street use often becomes unpleasant mainly by the encounter between pedestrians and motorists (or bikers, cyclists), but in China vehicles are on the top of the priority list, so pedestrians have to stop (Fig. 4).

In spite of this, streets as public surfaces possess unlimited possibilities. Constantly wandering street hawkers, patchwork-like shops overhanging from the ground floor, clothes typically hung out in the street, or tooth brushing can enrich the image. Streets can become rubbish-heaps from one moment to another. The traditional street functions as a market and it is the lengthened common space of the narrow inner spaces, where within certain limits, several activities can be imagined (Fig. 5).

Pedestrian streets, restricted from road traffic, are special cases of streets. 'Shopping streets' nearly always fill up with people, thus providing huge economic potential for its shops. There are almost no buildings where long queues of people would not be seen at the entrances and bare facades are almost as rare. There are no surfaces, which would not attempt to encourage pedestrians to buy.

The main street of Shanghai, Nanjing road (often called as the main street of Asia) and its facade reflects the face of traditional European architecture, however behind its wall, shopping centers of different sizes lure crowds of customers to this place. This atmosphere fades quickly in the joint alleys and living spaces. The main street is an emphatic urban element, interestingly constructed according to the perceptible motoristtraffic separation principles. In the middle of its intersection, there is a linear resting space and a lane of trees, which divides the crowds of people on both one and the other side of the street, as it would be a pedestrian 'highway'. The feeling is further strengthened by the size of the traffic lights used by pedestrians, which normally direct cars, but it is understandable in case of a huge number of people that large signals are needed (Fig. 6, Fig. 7). 


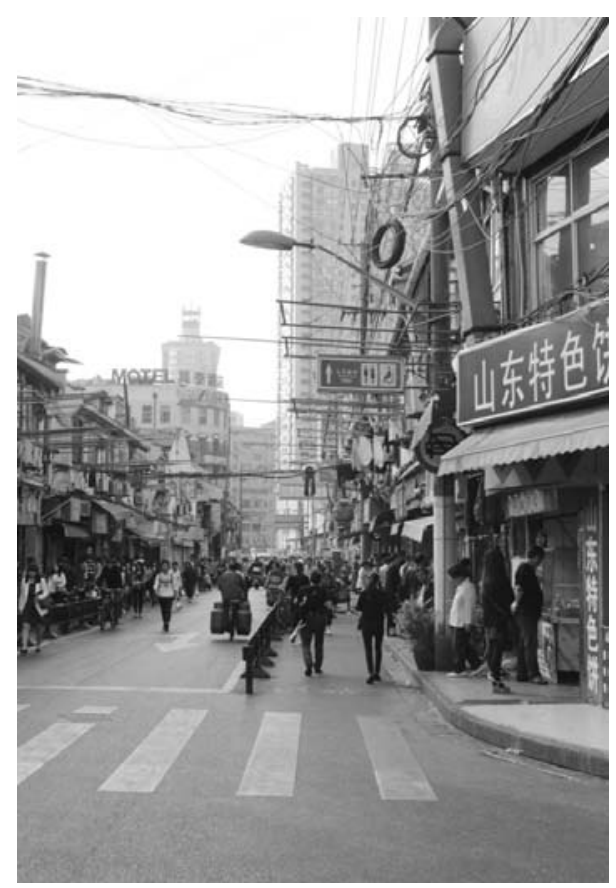

Fig. 4. Mixed-use street - pedestriancyclist-biker-motorist use - where pedestrians do not have privileges. The airspace rate of the street view becomes chaotic and overbuilt by cables, simple metal structures (typically for clothes) and information surfaces,

Source: János Gyergyák

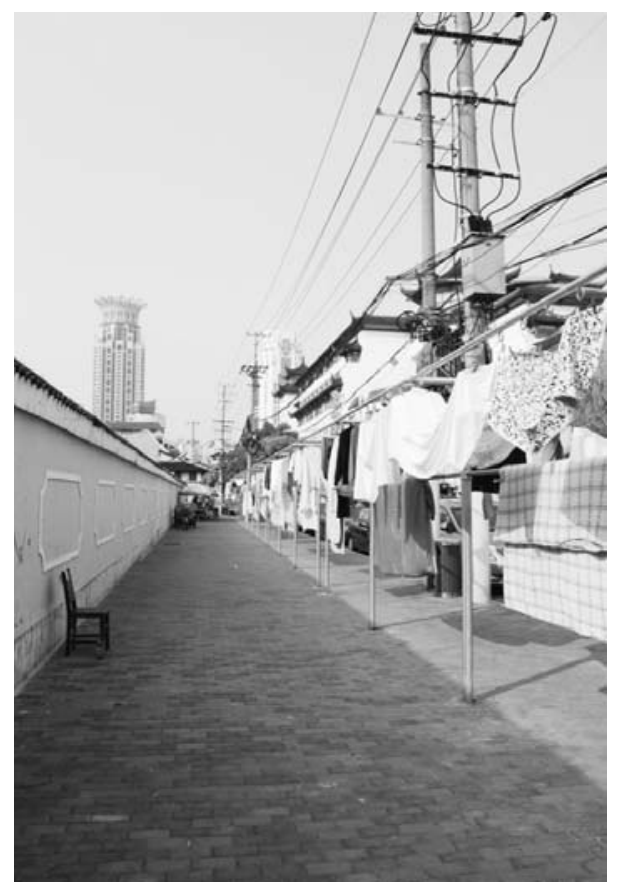

Fig. 5. The street is the location of several activities and even personal occasions: due to the narrow inner spaces, some activities

like hanging out clothes occur also in common spaces, Source: János Gyergyák

In terms of urban structures, lilongs have a less significant role (linear unbroken rows and their intermediate spaces), however they can always be perfect places for immediate hiding or protection in contrast with the busy urban lifestyle. The agglomeration of dwelling-houses, which were constructed in massive numbers in the second part of the $19^{\text {th }}$ century up until the 1930s. These buildings came into being by means of western row-houses and the urban architecture of South China. Lilongs were named after interior, linear and alley-like streets. Local communities were and are organized by the strong principles of these 'inner' streets. These spaces function as 'hallways' to a bigger block.

The space for storing motorbikes and bicycles is both suitable for minor occasions or playing cards and for peeling potatoes as well, while neighbors hang out their freshlywashed clothes to dry in front of the house or in the window. These slum-like constructions work as villages and not as a city within a city (city village). The gradual transformation of Shanghai can cause the disappearance of these unique and strong neighborhoods. The agglomeration of little town nature, containing blocks of one or 
two-storey houses, is constantly being demolished to replace it with new buildings. These new architectural forms, apart from one or two exceptions, lack public spaces, so the amount of still-existing intimate spaces is continuously decreasing (Fig. 8, Fig. 9).

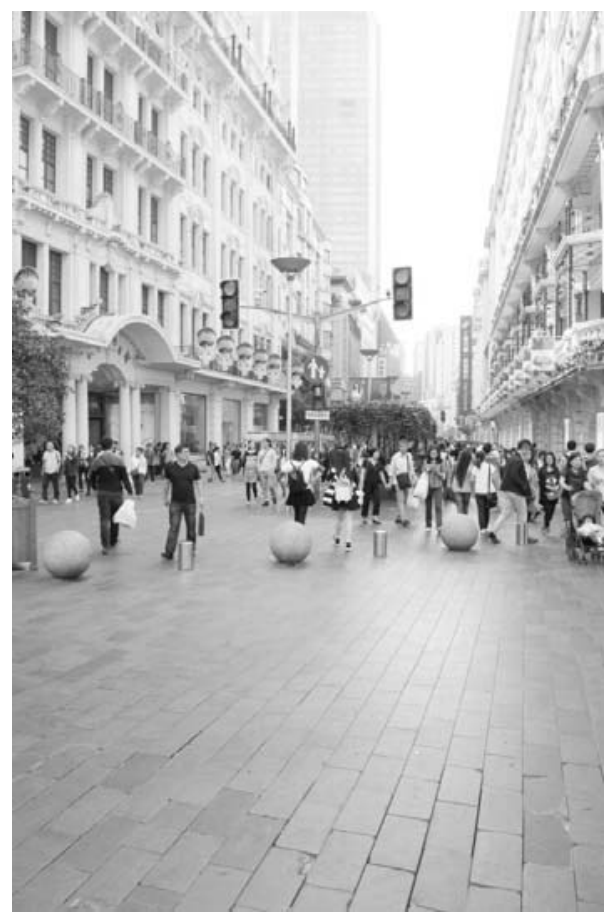

Fig. 6. A part of the shopping street of Nanjing road in Shanghai. The pedestrian mass is directed by traffic lights, at those places where it is intersected with a road. The uniform pedestrian surface nicely encloses the eclectic, neoclassical and art deco rows of buildings, Source: János Gyergyák

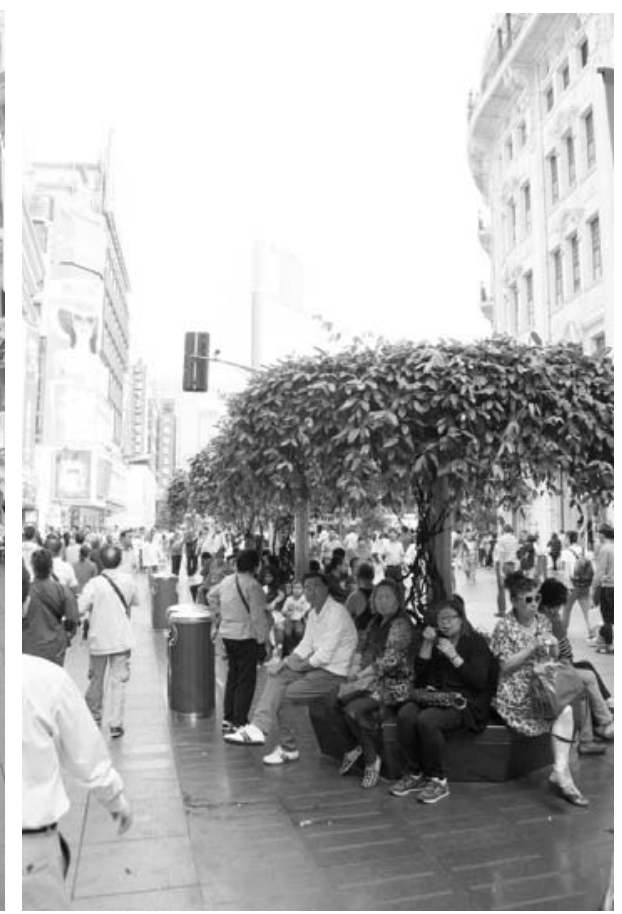

Fig. 7. In the middle lane of the intersection belonging to the shopping street, there are benches and seating surfaces alongside the entire street and smaller green lanes divide the space. This linear space divides the pedestrian mass into two traffic lanes, Source: János Gyergyák)

The inner agglomerations of blocks become increasingly popular from the point when they are available for the public. XinTiandi, which is known as the 'old street of Shanghai' reflects the atmosphere of a city from the turn of the century in modern surroundings, where the little town nature of the past, with its brick facade architecture, can coexist with the contemporary interior spaces of high aesthetics. Favored by both the local youth and foreigners, imposing shops, galleries, restaurants and bars can be found in the most well-known pedestrian street. Tianzifang, which is located in the French concession area, is similar to the previously mentioned one and it is a certain type of art market. It is a tiny 'market', where the old residential buildings have 
transformed into a shopping area by unified policies and possesses pleasant atmosphere on a human scale (Fig. 10, Fig. 11).

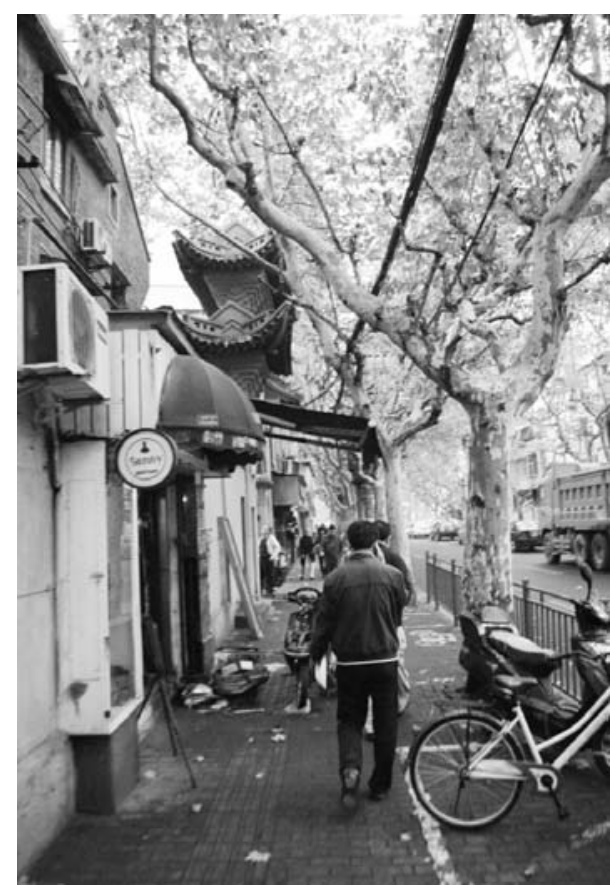

Fig. 8. Street view between the unique lilongs of Shanghai, which conserve the calmness of inner spaces, Source: János Gyergyák

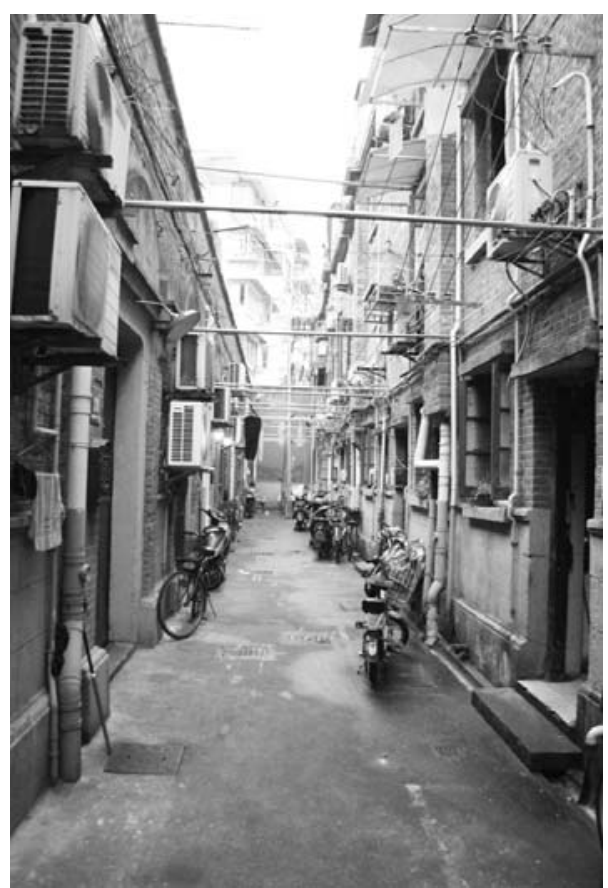

Fig. 9. The interior spaces of lilongs (linear unbroken rows and their intermediate spaces), alley-like spaces, these are the common places of the local communities, which are the expansions of the narrow interior spaces, Source: János Gyergyák

\subsection{Squares}

Squares possess a significant functional role in the urban fabric, which perhaps are one of the most important architectural manifestations of life and structure in certain societies. In the present time China squares belong to expanded streets, or they are the surfaces of bigger crossroads. It is somewhat rare that they form regular or nearly regular-shaped squares, they are rather considered as propaganda messages.

The center of Shanghai is People's Square, which is a space of 14 acres in the downtown and the most significant public square. The most emphatic spot of the square (or rather park) is the new city hall, whereas in front of this in the south the Shanghai Museum can be found. The prominent buildings of the Grand Theatre lies in the south, the Shanghai Urban Planning Exhibition Center in the east (which represents the 
gigantic 3 dimensional model of the city) in the close proximity of the city hall. The surface of the square is decorated with vegetation, flowers, water, statues, lamps and rockery. The square, which is in fact a bigger park, can be considered as the political and cultural center of Shanghai, but from an urban structural point of view and due to its sights, it is one of the main attractions.

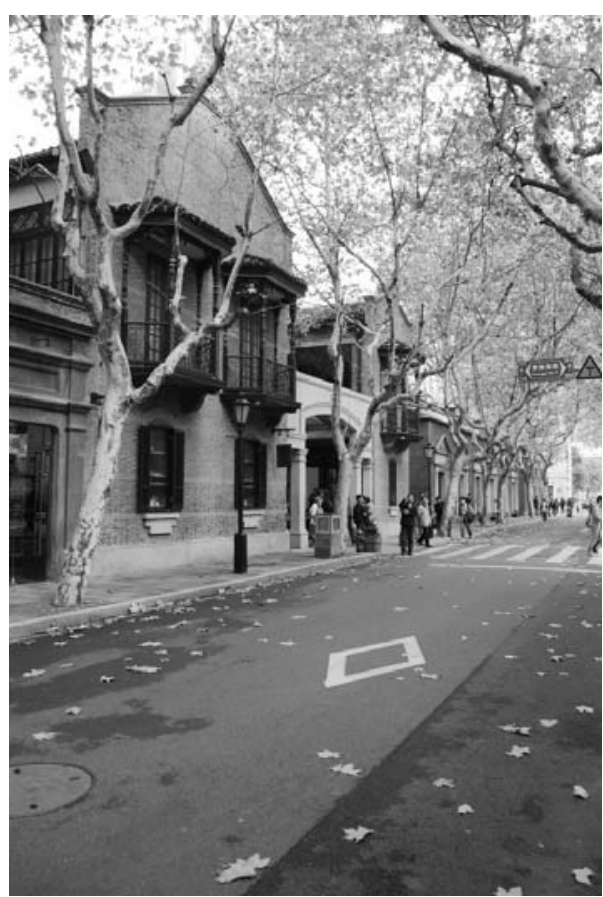

Fig. 10. Xintiandi district and its cozy street view. This is the area of the traditional shikumen Lilongs, where the space between buildings is car-free. It is also the region of shopping and restaurants, Source: János Gyergyák

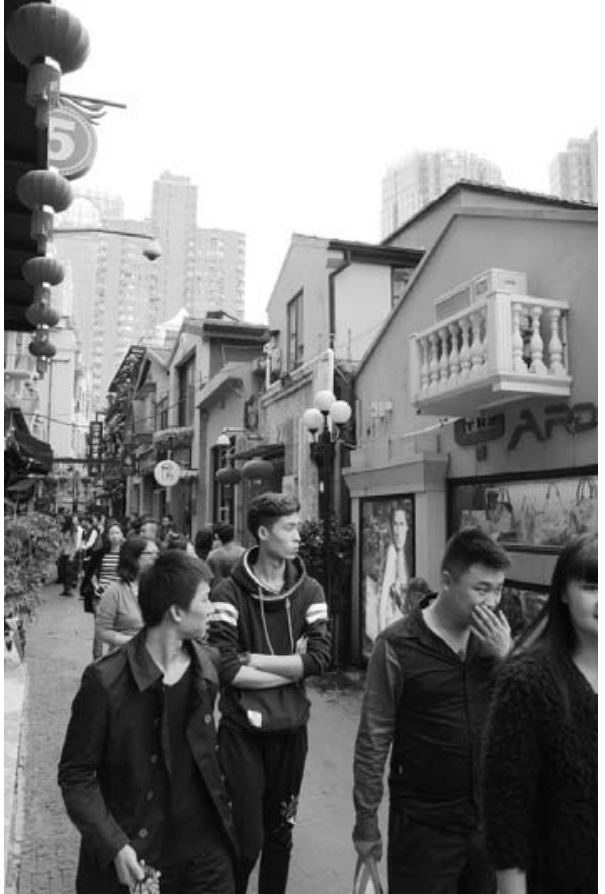

Fig. 11. Shanghai, the former residential area Tianzifang (shikumen lilongs) and its art market (center) or design market. Nowadays it is the home of popular bars, restaurants, shops and galleries, Source: János Gyergyák

The historical inner spaces of the present day Shanghai were constructed in the French concession era according to eclectic and Neo-Baroque principles. They were often raised as foregrounds of some buildings, without functions.

The squares in the surroundings of newly-built blocks and constructions can be understood with great difficulties. The public spaces, which were born on behalf of 'modern', cannot be regarded as real urban structures thus new constructions, tediously big distances between facades, due to the gaps between buildings, spaces are overwhelmed and imperceptible (Fig. 12, Fig. 13). 


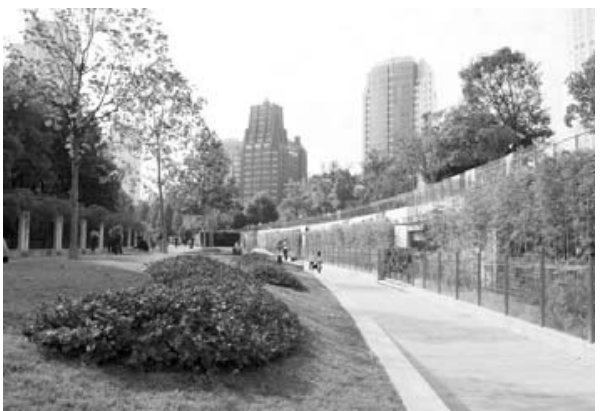

Fig. 12. People's square and its inner areas with the Park Hotel in the background, the prominent work of László Hudec, Source: János Gyergyák

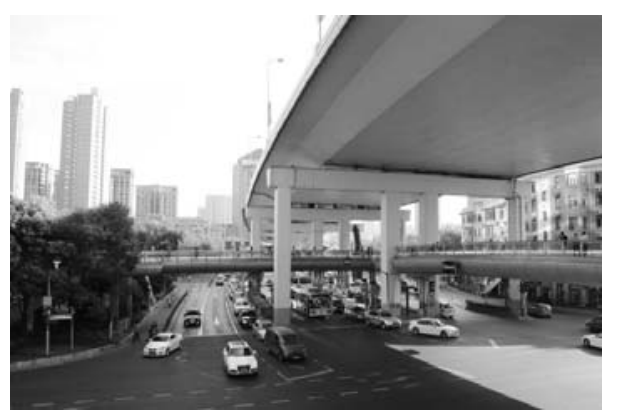

Fig. 13. Urban spaces as an important multistory hub, Source: János Gyergyák

\subsection{Parks-gardens}

The proportion of green surfaces within the urban fiber is varied. In the formerly constructed areas the proportion of inherited gardens (for example Yu Garden) and parks (People's Square, Fuxing Park) is satisfying. The urban-afforestation program in the old French concession parts created a pleasant microclimate. Surrounded by walls, traditional Chinese gardens in the heart of the city can still provide sudden and new experiences. The interior spaces of houses and pavilions, extended by outdoor spaces offer a chance for looking around and being isolated from the outside world. The romantic landscape of the Chinese garden turns into a place for relaxation by means of hills, rocks, vegetation, the harmony of water and smaller pavilion-like structures. It allows its people to hide from the urban hustle and bustle. The Chinese garden has always played a significant role in the culture of China and served as a vital place for leaders and artists of the society throughout history. Gardens are the primary locations for families and social life. It has changed recently, since these gardens offer shelter for anyone from urban 'brutalism', so they are priceless, therefore by their environment the urban fabric becomes more valuable (Fig. 14, Fig. 15).

On the other hand, in the newly-built areas the proportion of green surfaces is restricted to a minimum level. Gardens and parks are not typical with a major exception, which is the City Park in Pudong district.

\subsection{Waterside}

The most significant green space developments have occurred alongside the river. The areas, which were exploited by trade and industry for the last centuries, are returned to nature and the local inhabitants. The most considerable social developments of Shanghai are being carried out alongside river Suzhou and Huangpu, the latter is connected to the areas of Expo 2010 from the north and the south sides of the river. 


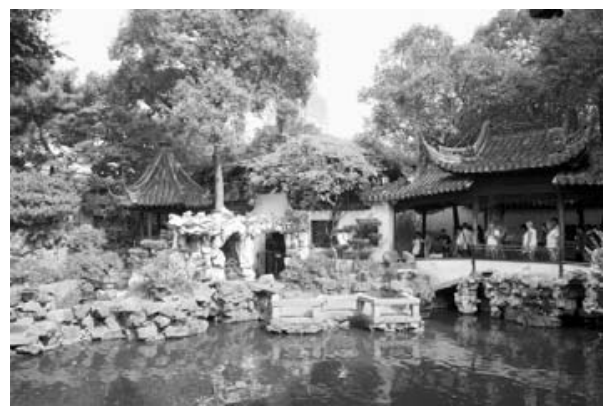

Fig. 14. The ancient garden of Shanghai, the picturesque view of Yu Garden in the heart of the city, Source: János Gyergyák

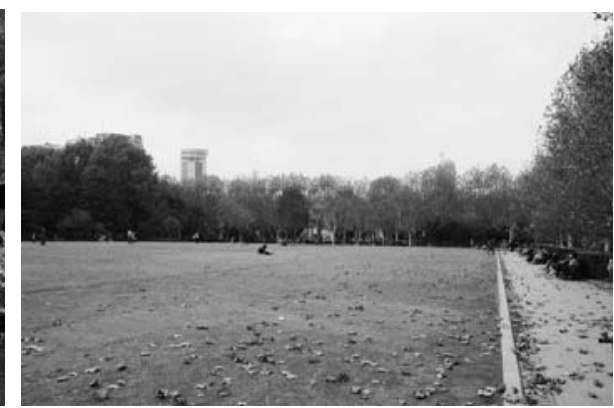

Fig. 15. One of the biggest green surfaces of the inner areas in Shanghai is the Fuxing Park, created by the French, Source: János Gyergyák

The rehabilitation of the northern bank of the river includes a waterfront area of nearly $13.3 \mathrm{~km}$. This process, affecting both banks of the river, renews the connection between river and city with a part of $28.1 \mathrm{~km}$, offering external spaces for the inhabitants of the city. At the encounter of Huangpu and Yangtze rivers, a petrol chemical plant is going to be built in tandem with an integrated ecological zone. The other parts of the location are going to be the center for the competitors of the innovative green industry, which is destined to improve the local ecology in parallel with providing modern industrial services. The rehabilitation of the middle and central areas alongside the river is the key element of the development. It covers the section from Lupu Bridge to Wuzhou Avenue-Xiangyin, which is an area of $19.4 \mathrm{~km}$ and it renews $22.6 \mathrm{~km}$ of the riverbank. The development plans have been carried out according to the 'waterside to everyone' principle. Within the framework of this program, a heterogeneous natural and ecological corridor has been formed on each bank of the river to offer waterfront surfaces for community programs, recreational activities and tourists of course. The area is going to be bordered with pronounced buildings divided into 20 units, alongside the Pudong in the east, Puxi district in the west, developing both banks of the river (Fig. 16, Fig. 17).

The importance of the river for Shanghai is considerable in terms of economy and strategy. At the lower sections, with its $400 \mathrm{~m}$ width and $9 \mathrm{~m}$ depth the river offers appropriate anchoring possibilities for marine vessels, thus it had a key significance in founding the settlement, later establishing foreign facilities and in the end, becoming a metropolis.

\subsection{Urban farms}

Instead of the consciously generated urban life, 'urban rurality' can be observed at several places. Due to the current oversupply, the consecutively built shopping centers and their message bring people closer to nature (and countryside). New commercial hubs are built, which are more similar to former and historical structures in terms of space. Instead of creating vast surfaces of buildings, piles, bordered by gaps, are 
designed. They are connected under the ground, however on the surface they form semicozy gaps, alleys with their fragmented construction. Their ideal height establishes the atmosphere of a little town (Fig. 18).

Another attempt to discharge the strong urban landscape is to connect the indoor 'private' spaces of shopping centers to nature. Urban inhabitants, excluded from nature, are served with the view of natural environment in interior spaces, thus forming an ambivalent feeling of an 'urban countryside' by means of a living or lifeless green environment within the inner and protected spaces of buildings (Fig. 19).

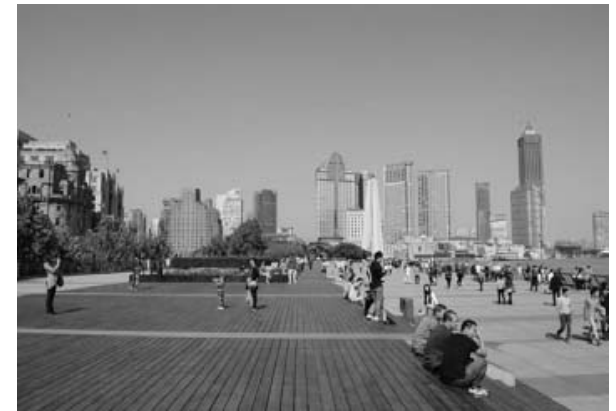

Fig. 16. The most frequented area of Shanghai, the promenade alongside the Bund. The most important rehabilitation of the inner section of river Huangpu is the surface on the water barrier, a protection from flood, Source: János Gyergyák

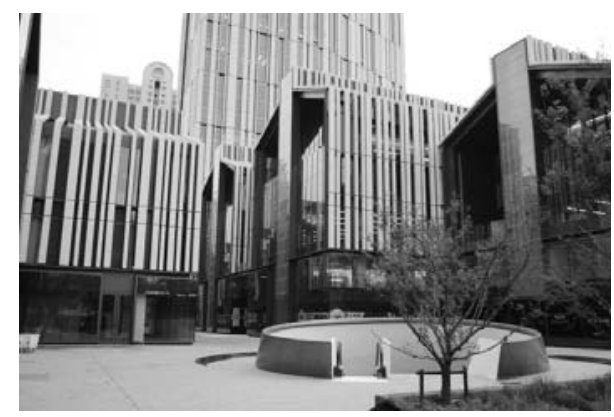

Fig. 18. The new building of Soho, one of the shopping centers in Shanghai. Instead of a 'pie' form, it has a nature of a little town, with constructions reminiscent of the typical lilongs, Source: János Gyergyák

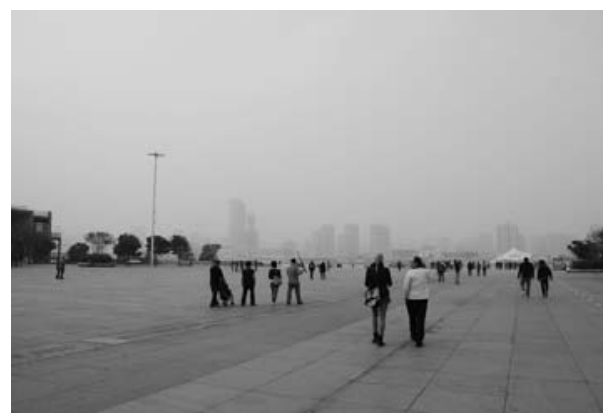

Fig. 17. The waterfront rehabilitation of the area belonging to Shanghai Expo, Source: János Gyergyák

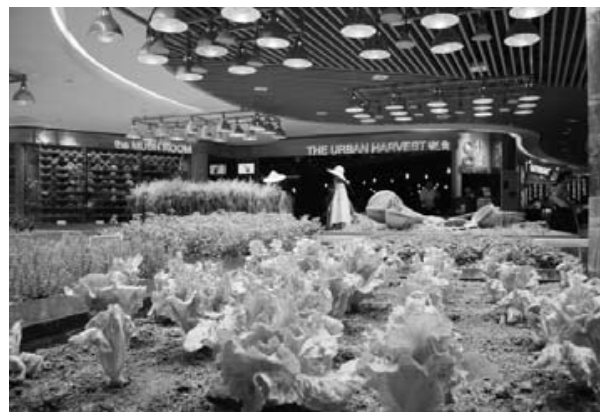

Fig. 19. An urban farm, which can be found in one of the exclusive shopping centers of Shanghai, in K11, Source: János Gyergyák 
Alterations resulted mainly in possessing narrower public spaces. The noisy, 'smelly' and 'constantly-speaking' streets have considerably transformed. The growing reconstruction of blocks conquers more and more space, whereas the major part of the city is being renewed slowly and it is losing its old-style, cozy and small-scale areas (Fig. 20).

The pre-existing lilongs and former constructions are disappearing. The new facades, formed by these developments, do not follow the human-scale traditions of Chinese architecture. These facades are growing and becoming closed. The newlyconstructed public spaces are attractive and eye-catching in most of the cases, however they cannot be considered as real spaces traditionally, and therefore their use is rare and difficult. Their rhythm begins to lose their human-scale (Fig. 21).

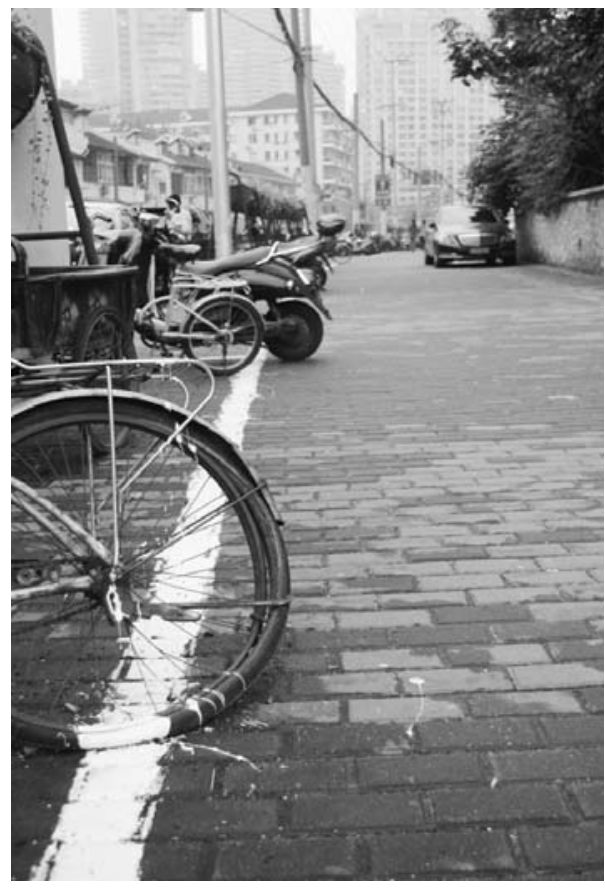

Fig. 20. A perfect picture for representing the unstoppable dash for growth in Shanghai, Source: János Gyergyák

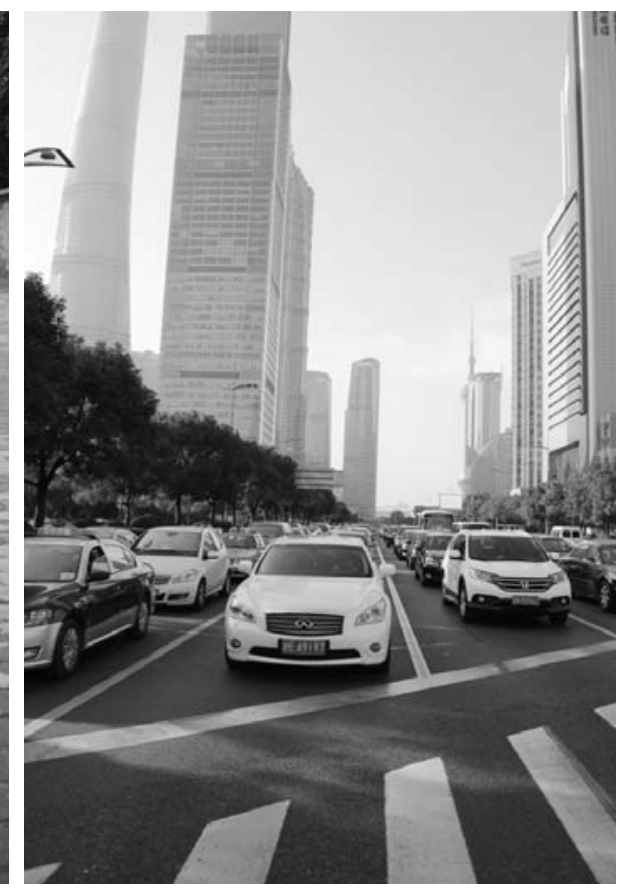

Fig. 21. The new main street of Shanghai, the Central Avenue in Pudong district. 2 times 5 lanes between the rows of skyscrapers, structurally the most important avenue, Source: János Gyergyák

\section{Conclusion}

The urban developments will have divided Shanghai into 4 centers by 2021, namely: international economic center, international financial center, international maritime 
center and international commercial center. In order to achieve this goal, the city is about to perform some serious improvements, although it is not known yet how these further expansions affect the built environment of Shanghai. The direction really does matter, since Shanghai will be one of the most noticeable cities of urban architecture in the $21^{\text {th }}$ century, which offers an example for developing cities with the same purpose.

In Europe, cities attempt to stop their territorial growth and focus on the compact nature of their inner areas. On the other hand, most of the Asian cities, in tandem with the vast economic and population increase, tend to expand the city network and the number of residents. The latter is completely understandable though. Industrial cities and agricultural rural lands show huge differences in living. By means of several developments Shanghai is keen to expand its capacity and available services, however it is concerned that achieving the desired goals can severely damage the inner structure of the city and its local traditional values.

Through the transformation of the city, a new center of market economy can come into being, although its image is becoming completely global with forgetting every ideal, which once used to be a proud source of Chinese culture and history.

\section{Acknowledgements}

The research work has been sponsored by the National Excellence Program providing personal benefits for students and researchers. The project was rationalized by means of European Union support and co-financed by the European Social Fund. Number of the competition A2-EPFK-13-0065.

\section{References}

[1] Sha Y., Wu J., Ji Y., Chan S. L. T., Lim W. Q. Shanghai urbanism at the medium scale, Springer, Berlin, 2014

[2] Mark Y. W., Pookong K., Jia G. (Ed) Transforming Chinese cities, Routledge, NY, 2014.

[3] Sun P. (Ed) The history of Shanghai urban planning, Shanghai Academy of Social, Science Press, Shanghai, 1999. 